\title{
Transition-metal-free visible light-promoted photoredox oxidative dehydrogenative cyclization: expeditious approach to 1,2,4-thiadiazoles
}

\author{
Zhiqiang Xiong, Qihao Zhong, Shouri Sheng, and Junmin Chen* \\ College of Chemistry \& Chemical Engineering, Jiangxi Normal University, Nanchang, Jiangxi 330022, China \\ Email: jxnuchenjm@163.com
}

Received 06-22-2021

Accepted Manuscript 08-15-2021

Published on line $08-25-2021$

\section{Abstract}

A novel visible-light-catalyzed oxidative $\mathrm{N}-\mathrm{S}$ bond formation for the synthesis of 3,5-disubstituted 1,2,4thiadiazoles has been developed. This protocol features a metal-free approach, green oxidant, room temperature process, broad substrate scope, good functional group tolerance, excellent yields and a one-pot reaction without the isolation of the intermediates.

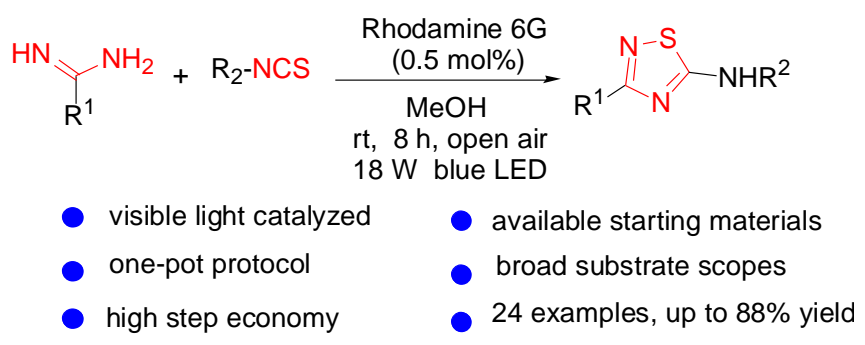

Keywords: Metal-free, photoredox, oxidative S-N bond formation, 1,2,4-thiadiazole 


\section{Introduction}

Thiadiazoles are an important class of five-membered heterocyclic motifs containing two nitrogen atoms and a sulfur atom, that are associated with a broad spectrum of biological and pharmacological activities. ${ }^{1-3}$ Among them, the 1,3,4-thiadiazoles have emerged as an important structural moiety present in a large number of functionalized molecules with a broad range of biological activities, such as anticancer, ${ }^{4-5}$ antimicrobial, ${ }^{6}$ anticonvulsant, ${ }^{7}$ fungicidal, ${ }^{8}$ antihepatitis B virus, ${ }^{9}$ and anti-HIV activity. ${ }^{10}$ Moreover, they are also found in valuable pharmaceuticals, including sitagliptin, ${ }^{11}$ maraviroc, ${ }^{12}$ trizaolam, ${ }^{13}$ deferasirox, ${ }^{14}$ and cefozopran ${ }^{15}$ (Figure 1).

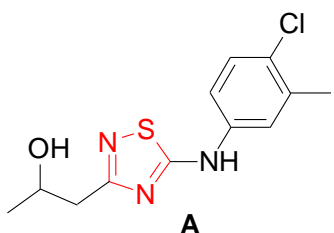

Neuroprotective activity

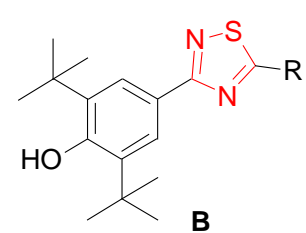

Cyclooxygenase Inhibitors

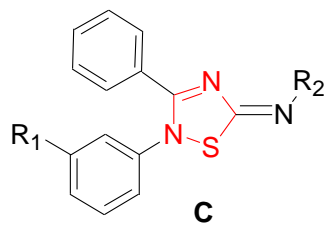

Human $A_{1}$ Inhibitors

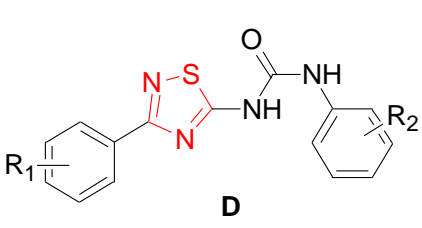

Adenosine $A_{1}$ receptor

Figure 1. Selected bioactive molecules that contain 1,3,4-thiadiazole skeletons.

Therefore, the synthesis of 1,2,4-thiadiazole derivatives has received considerable attention. The traditional method for the synthesis of 3,5-disubstituted 1,2,4-thiadiazoles relies on the oxidative dimerization reaction of thioamides using various oxidants (Scheme $1, a) \cdot{ }^{16-23}$ Recently, alternative methods were developed through intramolecular oxidative dehydrogenative cyclization by employing transition-metal or stoichiometric amount of oxidants such as hypervalent iodine (III), $\mathrm{I}_{2}$, or $\mathrm{O}_{2}$ (Scheme 1, b). ${ }^{24-31}$ Most recently, an elegant protocol has been published via the electro-oxidative intramolecular dehydrogenative $\mathrm{N}-\mathrm{S}$ bond formation of imidoyl thioureas (Scheme 1, c). ${ }^{32}$ Despite major progress in the field, the use of transition-metal catalysts or oxidants is still standard, which affects atom economy and environmental issues. Therefore, it is desirable to develop a more pratical and environmentally friendly method for the synthesis of 3,5disubstituted 1,2,4-thiadiazoles.

Previou work

$$
\text { Electro-oxidation }
$$

This work

$$
\underset{\text { bule LED }}{\text { Air }}
$$

Scheme 1. Different approaches to functionalized1,2,4-thiadiazoles. 
In recent years, visible-light photoredox catalysis has emerged as a powerful synthetic tool for mild and environmentally benign organic transformations. ${ }^{33-39}$ These attractive synthetic reactions are mainly spurred by exogenous photocatalysts to facilitate the conversion of visible light into chemical energy under exceptionally mild conditions. A variety of elegant photocatalyzed reactions for the construction of C-C and Cheteroatom bonds have been well established using visible-light using transition metal complexes or organic dyes as photoredox catalysts. ${ }^{40-48}$ Meanwhile, the application of photoredox catalysis for heteroatomheteroatom bond formation has attracted a lot of attention and has become a promising green approach to produce final products. ${ }^{49-52}$ Herein we report a direct and environmentally friendly method for the synthesis of 3-substituted-5-amino-1,2,4-thiadiazoles using Rhodamine 6G as an organophotoredox catalyst irradiated with blue LED light under an air atmosphere at room temperature (Scheme 1, d).

\section{Results and Discussion}

We initiated our studies by choosing $N$-(phenylcarbamothioyl)benzimidamide (1a) as a model substrate in the presence of $0.5 \mathrm{~mol} \%$ of $f a c-\mathrm{Ir}(\mathrm{bpy})_{3}$ in $\mathrm{CH}_{3} \mathrm{OH}$ at room temperature under air atmosphere. After $8 \mathrm{~h}$ of irradiation with a $18 \mathrm{~W}$ blue LED light, the desired dehydrogenative cyclization product 2a was obtained in $63 \%$ yield (Table 1, entry 1 ). Encouraged by this promising result, we next surveyed a range of photocatalysts under the same conditions (Table 1 , entries $2-7$ ). We found that the $\mathrm{Ru}(\mathrm{bpy})_{3} \mathrm{Cl}_{2}$ photocatalyst can slightly improve the efficiency for generation of $\mathbf{2 a}$ (71\%, Table 1, entry 2$)$. To develop a metal-free protocol, we then examined various organic dyes including eosin $Y$, methylene blue, rose bengal, 3DPAFIN (1,3-dicyano-2,4,5,6tetrakis(diphenylamino)benzene), and Rhodamine 6G (Table 1, entries 3-7). These results showed that the organic photocatalyst rhodamine $6 \mathrm{G}$ provided the best result (87\%, Table 1 , entry 7$)$. We then screened the reaction in various solvents such as $\mathrm{CH}_{3} \mathrm{CN}, \mathrm{DMF}, \mathrm{CH}_{2} \mathrm{Cl}_{2}, \mathrm{CH}_{3} \mathrm{CH}_{2} \mathrm{OH}$, and 1,4-dioxane (Table 1, entries 8-12). Interestingly, we found that these solvents can promote this reaction in good yield and that $\mathrm{CH}_{3} \mathrm{OH}$ was found to be the best choice. The reaction time was examined and the yield did not improve (88\%, Table 1, entry 13$)$. The amount of the photocatlayst was also investigated, and it was found that $0.5 \mathrm{~mol} \%$ catalyst loading was sufficient to furnish the product in excellent yields (Table 1, entries 14 and 15). Performing the reaction under oxygen atmosphere did not improve the product yield (Table 1, entry 16). Control experiments showed that the presence of the photocatalyst, air, and the light source is necessary for this transformation to proceed (Table 1, entries 17-19). Finally, we attempted to carry out the nucleophilic addition and oxidative cyclization in a one-pot fashion. To our delight, the desired product 2 a was also obtained in similar yield when the imidoyl thiourea 1a was formed in a preceding step from an aryl isocyanate in the same reaction vessel without isolation and under the optimal reaction conditions (Table 1, entry 20). 
Table 1. Screening of optimal reaction conditions $s^{a, b, c}$

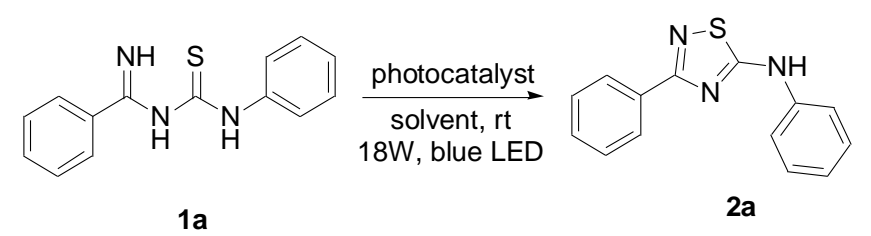

\begin{tabular}{|c|c|c|c|}
\hline Entry $^{a}$ & Photocatalyst & Solvent & Yield $(\%)^{b}$ \\
\hline 1 & $f a c-\operatorname{Ir}(\mathrm{bpy})_{3}$ & $\mathrm{CH}_{3} \mathrm{OH}$ & 63 \\
\hline 2 & $\mathrm{Ru}(\mathrm{bpy}){ }_{3} \mathrm{Cl}_{2}$ & $\mathrm{CH}_{3} \mathrm{OH}$ & 71 \\
\hline 3 & Eosin $Y$ & $\mathrm{CH}_{3} \mathrm{OH}$ & 72 \\
\hline 4 & Methylene blue & $\mathrm{CH}_{3} \mathrm{OH}$ & 68 \\
\hline 5 & Rose bengal & $\mathrm{CH}_{3} \mathrm{OH}$ & 23 \\
\hline 6 & 3DPAFIN & $\mathrm{CH}_{3} \mathrm{OH}$ & 79 \\
\hline 7 & Rhodamine 6G & $\mathrm{CH}_{3} \mathrm{OH}$ & 87 \\
\hline 8 & Rhodamine 6G & $\mathrm{CH}_{3} \mathrm{CN}$ & 81 \\
\hline 9 & Rhodamine 6G & DMF & 57 \\
\hline 10 & Rhodamine 6G & $\mathrm{CH}_{2} \mathrm{Cl}_{2}$ & 65 \\
\hline 11 & Rhodamine 6G & $\mathrm{CH}_{3} \mathrm{CH}_{2} \mathrm{OH}$ & 73 \\
\hline 12 & Rhodamine 6G & 1,4-dioxane & 71 \\
\hline $13^{c}$ & Rhodamine $6 G$ & $\mathrm{CH}_{3} \mathrm{OH}$ & 88 \\
\hline $14^{d}$ & Rhodamine 6G & $\mathrm{CH}_{3} \mathrm{OH}$ & 78 \\
\hline $15^{\mathrm{e}}$ & Rhodamine 6G & $\mathrm{CH}_{3} \mathrm{OH}$ & 89 \\
\hline $16^{f}$ & Rhodamine 6G & $\mathrm{CH}_{3} \mathrm{OH}$ & 88 \\
\hline $17^{g}$ & Rhodamine 6G & $\mathrm{CH}_{3} \mathrm{OH}$ & 0 \\
\hline $18^{\mathrm{h}}$ & Rhodamine 6G & $\mathrm{CH}_{3} \mathrm{OH}$ & trace \\
\hline $19^{i}$ & Rhodamine 6G & $\mathrm{CH}_{3} \mathrm{OH}$ & trace \\
\hline $20^{j}$ & Rhodamine 6G & $\mathrm{CH}_{3} \mathrm{OH}$ & 87 \\
\hline
\end{tabular}

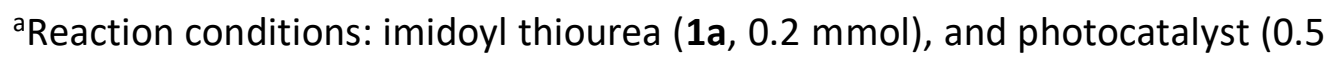
mol \%) in solvent $(2 \mathrm{ml})$ were irradiated with $18 \mathrm{~W}$ blue LEDs at room temperature in the open air for $12 \mathrm{~h}$. ' Isolated yields. 'Reaction time for $12 \mathrm{~h}$. dPhotocatalyst $(0.25 \mathrm{~mol} \%)$; ePhotocatalyst $(1.0 \mathrm{~mol} \%)$; ${ }^{\mathrm{f}}$ The reaction was

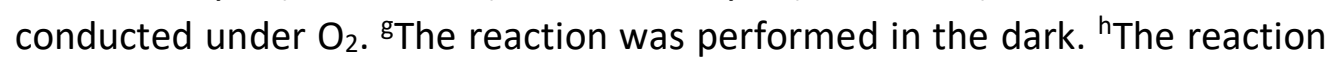
was conducted under $\mathrm{N}_{2}$. 'Reaction was performed without a catalyst. 'Onepot protocol. 3DPAFIN $=1,3$-dicyano-2,4,5,6tetrakis(diphenylamino)benzene.

With the optimal conditions (Table 1, entry 7) in hand, we next probed the scope and generality of this intramolecular oxidative S-N bond formation approach to a variety of 3-substituted-5-amino-1,2,4-thiadiazoles 
in a one-pot fashion and the results are summarized in Scheme 2. First, we investigated the scope of the $R$ substituent on aryl isothiocyanates. Various electron-donating and -withdrawing substituents including $p$-Me, p-OMe, $p$ - $\mathrm{F}, p-\mathrm{Cl}, p$ - $\mathrm{Br}, p-\mathrm{I}, m-\mathrm{Me}$, and $m-\mathrm{Cl}$, were well-tolerated, affording the corresponding 1,2,4thiadiazoles in good to excellent yields (2a-2i). Meanwhile, the 0 -methyl substituted isothiocyanates $\mathbf{1 j}$ had little influence on the reaction and afforded the desired product $\mathbf{2} \mathbf{j}$ in $73 \%$ yield.

Table 2. One-pot synthesis of 3-substituted-5-amino-1,2,4-thiadiazoles via in situ generated Imidoyl Thiourea ${ }^{a, b}$

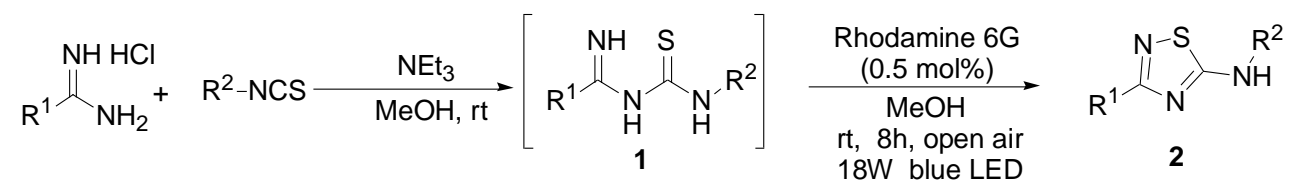
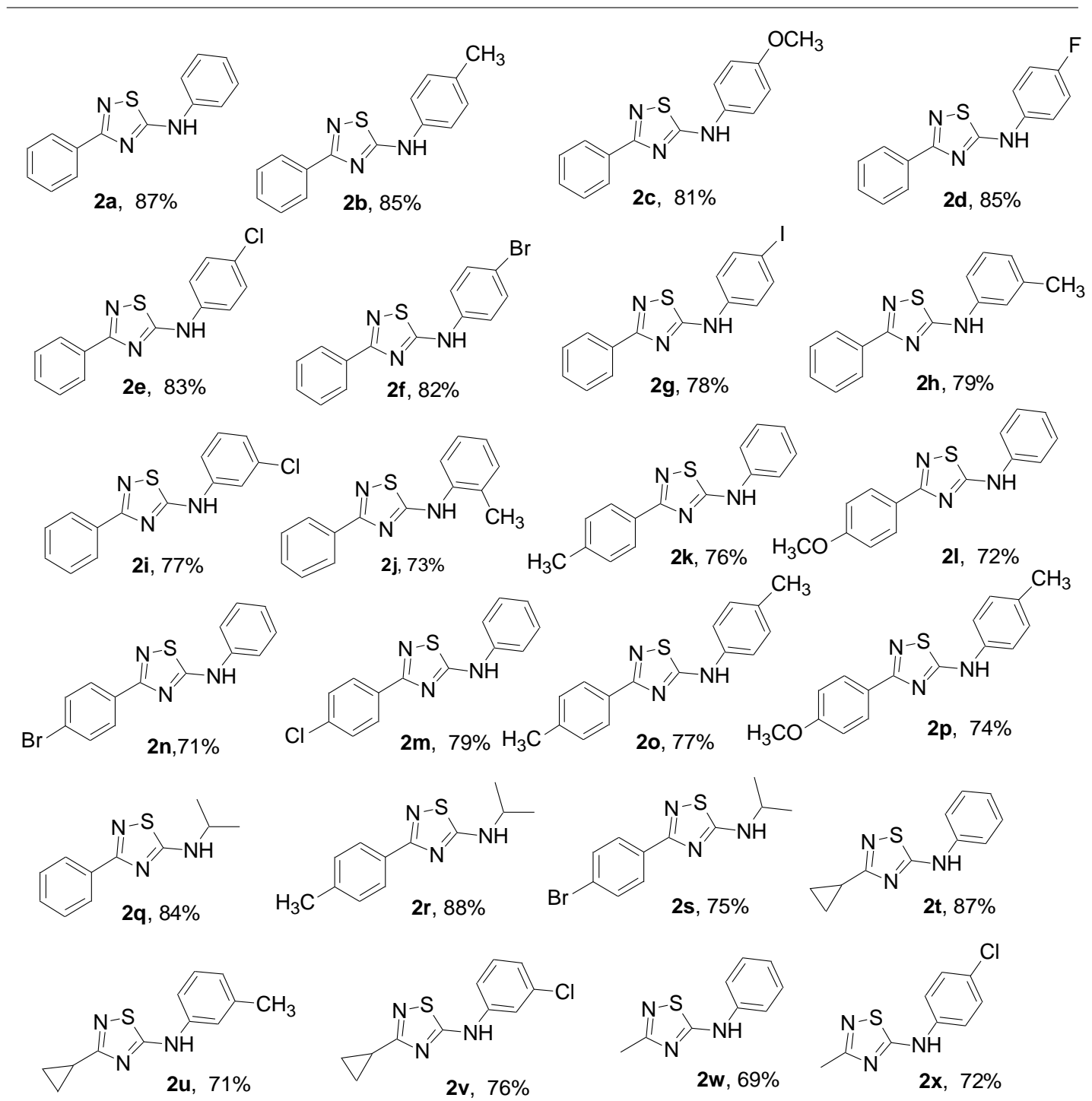

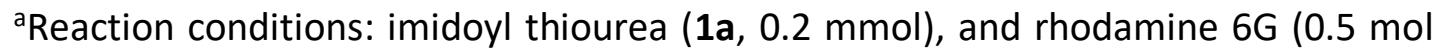
$\%$ ) in $\mathrm{CH}_{3} \mathrm{OH}(2 \mathrm{ml})$ were irradiated with $18 \mathrm{~W}$ blue LEDs at room temperature in the open air for $8 \mathrm{~h}$. ' Isolated yields. 
Next, we investigated the scope of the $R$ substituent on phenyl amidines. A range of substrates bearing electron-donating or electron-withdrawing group-substituted aromatic rings all underwent the oxidative dehydrogenative cyclization smoothly and gave the desired products in very good yields (2k-2m). Moreover, both various substituted amidines and isothiocyanates could provide the desired products in $77 \%$ and $74 \%$ yield (2o and $\mathbf{2 p}$ ), respectively. Furthermore, alkyl isothiocyanates such as isopropyl isothiocyanate were compatible with the optimized conditions as well, affording the desired products $\mathbf{2 q - 2 s}$ in excellent yields. Interestingly, alkyl amidines such as cyclopropyl and methyl amidine reacted smoothly, affording the desired products $\mathbf{2 t - \mathbf { x }}$ in very high yields.

\section{Conclusions}

In conclusion, we have developed a metal-free, visible-light induced organophotoredox-catalyzed dehydrogenative cyclization protocol for the intramolecular N-S bond formation using rhodamine $6 \mathrm{G}$ as a photocatalyst under aerobic reaction conditions. A broad range of 3-substituted 5-amino-1,2,4-thiadiazole derivatives are conveniently synthesized in good to excellent yields with good functional group tolerance, Further investigation for other heterocyclic syntheses based on this photocatalytic protocol is underway in in our laboratory.

\section{Experimental Section}

General procedure for 3,5-disubstituted 1,2,4-thiadiazoles 2. In an oven-dried single-necked bottle (10 mL) equipped with a stir bar, amidine hydrochloride $(0.2 \mathrm{mmol})$, isothiocyanate $2(0.2 \mathrm{mmol}), \mathrm{NEt}_{3}(0.4 \mathrm{mmol})$, and $\mathrm{CH}_{3} \mathrm{OH}(2 \mathrm{~mL})$ were added and stirred at room temperature until the conversion was completed as indicated by TLC. Then, rhodamine $6 \mathrm{G}(0.5 \mathrm{~mol} \%)$ was added, the reaction mixture was open to the air and stirred at room temperature under the irradiation of a $18 \mathrm{~W}$ LED lamp for $8 \mathrm{~h}$. After completion of the reaction, the resulting mixture was extracted with EtOAc and the organic phase was then removed under vacuum. The residue was purified by flash column chromatography using a mixture of petroleum ether and ethyl acetate as eluent to give the desired products 2.

Compounds 2a-x are known compounds and their spectral data are in agreement with those reported in the literature (see also the Supplementary Material file)

\section{Acknowledgements}

This work was supported by grants from the National Natural Science Foundation of China (Grant No. 21762022). 


\section{Supplementary Material}

Copies of $1 \mathrm{H}$ NMR spectra of compounds $\mathbf{2 a - x}$ are given in the supplementary material file associated with this paper.

\section{References}

1. Li, Y.; Geng, J.; Liu, Y.; Yu, S.; Zhao, G. ChemMedChem. 2013, 8, 27-41. https://doi.org/10.1002/cmdc.201200355

2. Kumar, D.; Kumar, N. M.; Chang, K. H.; Shah, K. Eur. J. Med. Chem. 2010, 45, 4664-4668. https://doi.org/10.1016/j.ejmech.2010.07.023

3. A. I. Rosenbaum, C. C. Cosner, C. J. Mariani, F. R. Maxfield, O. Wiest, P. Helquist, J. Med. Chem. 2010, 53, 5281-5289.

4. Arsenyan, P.; Rubina, K.; Shestakova, I.; Domracheva, I. Eur. J. Med. Chem., 2007, 42, 635-640. https://doi.org/10.1016/j.ejmech.2006.12.004

5. Bondock, S.; Fadaly, W.; Metwally, M. A. Eur. J. Med. Chem., 2009, 44, 4813-4818. https://doi.org/10.1016/i.ejmech.2009.07.024

6. Huang, W.; Yang, G. Bioorg. Med. Chem., 2006, 14, 8280-8285.

7. Stillings, M. R.; Welbourn, A. P.; Walter, D. S. J. Med. Chem., 1986, 29, 2280-2284.

8. Kumita, I.; Niwa, A. J. Pestic. Sci., 2001, 26, 60-66.

9. Dong, W.; Liu, Z.; Liu, X.; Li, Z.; Zhao, W. Eur. J. Med. Chem., 2010, 45, 1919-1926. https://doi.org/10.1016/j.ejmech.2010.01.032

10. Zhan, P.; Liu, X.; Fang, Z.; Li, Z.; Pannecouque, C.; DeClercq, E. Eur. J. Med. Chem., 2009, 44, 4648-4653. https://doi.org/10.1016/j.ejmech.2009.06.037

11. Yang, B.; Cao, L.; Fang, R.; Gu. Z. Eur. J. Pharmacol. 1999, 380, 145-152.

12. Mulakayala, N.; Reddy, C. U.; Iqbal, J.; Pal, M. Tetrahedron 2010, 66, 4919-4938. https://doi.org/10.1016/i.tet.2010.04.088

13. Li, C.-S.; An, C.-Y.; Li, X.-M.; Gao, S.-S.; Cui, C.-M.; Sun, H.-F.; Wang, B.-G. J. Nat. Prod. 2011, 74, $1331-1334$. https://doi.org/10.1021/np200037z

14. Nisbet-Brown, E.; Olivieri, N. F.; Giardina, P. J.; Grady, R. W.; Neufeld, E. J.; Sechaud, R.; Krebs-Brown, A. J.; Anderson, J. R.; Alberti, D.; Sizer, K. C.; Lancet 2003, 361, 1597-1602.

https://doi.org/10.1016/S0140-6736(03)13309-0

15. lizawa, Y.; Okonogi, K.; Hayashi, R.; Iwahi, T.; Yamazaki, T.; Imada, A. Agents Chemother. 1993, 37, $100-105$. https://doi.org/10.1128/AAC.37.1.100

16. Shah, A. A.; Khan, Z. A.; Choudhary, N.; Loholter, C.; Schafer, S.; Marie, G. P. L.; Faroog, U.; Witulski, B.; Wirth, T. Org. Lett. 2009, 11, 3578-3581.

https://doi.org/10.1021/ol9014688

17. Cashman, J.-R.; Hanzlik, R.-P. J. Org. Chem. 1982, 47, 4645-4650. https://doi.org/10.1021/jo00145a008

18. Patil, P. C.; Bhalerao, D. S.; Dangate, P. S.; Akamanchi, K. G. Tetrahedron Lett. 2009, 50, 5820-5822. https://doi.org/10.1016/i.tetlet.2009.07.155

19. Khosropour, A.-R.; Noei, A. Monatsh. Chem., 2010, 141, 649-651. https://doi.org/10.1007/s00706-010-0295-3 
20. Cheng, D.; Luo, R.; Zheng, W.; Yan, J. Synth. Commun., 2012, 42, 2007-2013. https://doi.org/10.1080/00397911.2010.551287

21. Kim, H.-Y.; Kwak, S. H.; Lee, G.-H.; Gong, Y.-D. Tetrahedron 2014, 70, 8737-8743. https://doi.org/10.1016/j.tet.2014.09.023

22. Yang, L.; Song, L.; Tang, S.; Li, L.; Li, H.; Yuan, B.; Yang, G. Eur. J. Org. Chem., 2019, 1281-1285.

23. Gurjar, A. S.; Andrisano, V.; Simone, A. D.; Velingkar, V. S. Bioorgan. Chem., 2014, 57, 90-98. https://doi.org/10.1016/j.bioorg.2014.09.002

24. Chai, L.; Lai, Z.; Xia, Q.; Yuan, J.; Bian, Q.; Yu, M.; Zhang, W.; Xu, Y.; Xu, H. Eur. J. Org. Chem., 2018, 43384344.

25. Huang, Y.; Li, J.; Tang, X.; Wu, W.; Jiang, H. J. Org.Chem., 2018, 83, 9334-9343.

26. Tumula, N.; Palakodety, R. K.; Balasubramanian, S.; Nakka, M. Adv. Synth. Catal. 2018, 360, $2806-2812$. https://doi.org/10.1002/adsc.201800353

27. Wang, B;. Meng, Y.; Zhou, Y.; Ren, L.; Wu, J. ; Yu, W.; Chang, J. J. Org. Chem. 2017, 82, 5898-5903. https://doi.org/10.1021/acs.joc.7b00814

28. Mariappan, A.; Rajaguru, K.; Chola, N. M.; Muthusubramanian, S.; Bhuvanesh, N. J. Org. Chem. 2016, 81, 6573-6579.

https://doi.org/10.1021/acs.joc.6b01199

29. Tumula, N.; Jatangi, N.; Radha, K. P.; Balasubramanian, S.; Nakka, M. J. Org. Chem. 2017, 82, 5310-5316. https://doi.org/10.1021/acs.joc.7b00646

30. Jatangi, N.; Tumula, N.; Radha, K. P.; Nakka, M. J. Org. Chem. 2018, 83, 5715-5723. https://doi.org/10.1021/acs.joc.8b00753

31. Yang, Z.; Cao, T.; Liu, S.; Li, A.; Liu, K.; Yang, T.; Zhou, C. New J. Chem. 2019, 43, 6465-6468. https://doi.org/10.1039/C9NJ01419E

32. Yang, Z.; Zhang, J.; Hu, L.; Li, L.; Liu, K.; Yang, T.; Zhou, C. J. Org. Chem. 2020, 85, 3358-3363. https://doi.org/10.1021/acs.joc.9b03155

33. Nicewicz, D. A.; MacMillan, D. W. C. Science 2008, 322, 77-80. https://doi.org/10.1126/science.1161976

34. Narayanam, J.; Stephenson, C. Chem. Soc. Rev. 2011, 40, 102-113.

35. Prier, C. K.; Rankic, D. A.; MacMillan, D. W. C. Chem. Rev. 2013, 113, 5322-5363.

36. Skubi, K. L.; Blum, T. R.; Yoon, T. P. Chem. Rev. 2016, 116, 10035-10074. https://doi.org/10.1021/acs.chemrev.6b00018

37. Romero, N. A.; Nicewicz, D. A. Chem. Rev. 2016, 116, 10075-10166. https://doi.org/10.1021/acs.chemrev.6b00057

38. Xie, J.; Jin, H.; Hashmi, A. Chem. Soc. Rev. 2017, 46, 5193-5203. https://doi.org/10.1039/C7CS00339K

39. Xu, P.; Li, W.; Xie, J.; Zhu, C. Acc. Chem. Res. 2018, 51, 484-495. https://doi.org/10.1021/acs.accounts.7b00565

40. Jiang, M.; Yang, H.; Fu, H. Org. Lett. 2016, 18, 5248-5251. https://doi.org/10.1021/acs.orglett.6b02553

41. Zhang, Q.-B.; Ban, Y.-L.; Yuan, P.-F.; Peng, S.-J.; Fang, J.-G.; Wu, L.-Z.; Liu, Q. Green Chem. 2017, 19, 248 5559-5563.

42. Chakrasali, P.; Kim, K.; Jung, Y. S.; Kim, H.; Han, S. B. Org. Lett. 2018, 20, 7509-7513 https://doi.org/10.1021/acs.orglett.8b03273

43. Alam, R.; A.Molander, G. Org. Lett. 2018, 20, 2680-2684. 
44. Blank, L.; Fagnoni, M.; Protti, S.; Rueping, M. Synthesis 2019, 51, 1243-1252.

45. Wei, Z.; Qi, S.; Xu, Y.; Liu, H.; Wu, J.; Li, H.; Xia, C.; Duan, G. Adv. Synth. Catal. 2019, 361, 5490-5498. https://doi.org/10.1002/adsc.201900885

46. Yu, X.-Y.; Chen, J.-R.; Wang, P.-Z.; Yang, M.-N.; Liang, D.; Xiao, W.-J. Angew. Chem., Int. Ed. 2018, 57, 738743.

https://doi.org/10.1002/anie.201710618

47. Chen, W.; Liu, Z.; Tian, J.; Li, J.; Ma, J.; Cheng, X.; Li, G. J. Am. Chem. Soc. 2016, 138, 12312-12315.

48. Goti, G.; Bieszczad, B.; Vega-Penaloza, A.; Melchiorre, P. Angew. Chem., Int. Ed. 2019, 58, 1213-1217 https://doi.org/10.1002/anie.201810798

49. Yu, M. M.; Jing, H. Z.; Liu, X.; Fu, X. F. Organometallics 2015, 34, 5754-5758. https://doi.org/10.1021/acs.organomet.5b00521

50. Sahoo, M. K.; Saravanakumar, K.; Jaiswal, G.; Balaraman, E. ACS Catal. 2018, 8, 7727-773. https://doi.org/10.1021/acscatal.8b01579

51. Wang, X.; Wang, X.; Xia, C.; Wu, L. Green Chem. 2019, 21, 4189-4193. https://doi.org/10.1039/C9GC01618J

52. Wang, X.; Xia, C.; Wu, L. Org. Lett. 2020, 22, 7373-7377. https://doi.org/10.1021/acs.orglett.0c02746 